\title{
O POTENCIAL DE IMAGENS QUICKBIRD PARA ANÁLISE DO RELEVO DE UM SETOR DO PLANALTO DAS ARAUCÁRIAS, RS: CENTRO DE PESQUISAS E CONSERVAÇÃO DA NATUREZA PRÓ-MATA
}

Eduardo da Silva Pinheiro

Programa de Pós-graduação em Ciências da Engenharia Ambiental - EESC - CRHEA Universidade de São Paulo - USP. Caixa Postal 292. CEP 13560-790. São Carlos, SP Pinheiro_rs@yahoo.com.br

Hermann Johann Heinrich Kux

Instituto Nacional de Pesquisas Espaciais - INPE Pesquisador-Titular. Caixa Postal 515 - 12201-970. São José dos Campos, SP hermann@1tid.inpe.br

Jorge Alberto Villwock

Instituto do Meio Ambiente, Pontifícia Universidade Católica do Rio Grande do Sul - IMA/PUCRS

\begin{abstract}
Resumo
Este trabalho analisa o potencial de imagens com alta resolução espacial (satélite QuickBird) para mapear o relevo de um setor do Planalto das Araucárias, no nordeste do Rio Grande do Sul, Brasil. A área teste foi o Centro de Pesquisas e Conservação da Natureza PRÓ-MATA. Em 1994, o PRÓ-MATA foi criado para desenvolver estudos e ações visando à conservação da Mata Atlântica. Imagens QuickBird e técnicas de geoprocessamento foram usadas para executar o mapeamento. Foram realizados trabalhos de campo para conhecimento da área e levantamento de pontos de controle, utilizando GPS diferencial. As etapas do trabalho foram: gerar um Modelo Digital de Elevação (MDE), realizar fusão e corrigir a geometria das imagens QuickBird, mapear a hidrografia e a geomorfologia. A partir do MDE derivaram mapas de declividades, altimetria e visualizações em 3D da área de estudo. O mapa geomorfológico foi criado na escala de 1/15000, sendo considerados aspectos morfológicos e morfométricos do relevo. A rede de drenagem foi mapeada com detalhe. $\mathrm{Na}$ área de estudo, o relevo acidentado com altas declividades dificultaram a aquisição dos pontos de controle e a correção geométrica das imagens. Não obstante, a alta resolução espacial das imagens QuickBird permitiu mapear a área com detalhes, auxiliando na otimização dos trabalhos de campo. Os resultados demonstraram que as imagens com alta resolução são adequadas para analisar e mapear o relevo em áreas acidentadas.
\end{abstract}

Palavras-chave: Imagens QuickBird; Planalto das Araucárias; Mapa geomorfológico.

\begin{abstract}
This paper analyzes the potential of high-resolution images (QuickBird satellite) to mapping the relief features of a sector of the Planalto das Araucárias, an elevated area in northeastern Rio Grande do Sul, State, Brazil. The Center for Research and Nature Conservation PRÓ-MATA was chooses as an experimental area. In 1994, the PRÓ-MATA was created to perform studies and to propose actions for the conservation of the so-called Mata Atlântica. QuickBird data and GIS techniques were used to execute the mapping. Two field surveys were done to obtain ground-based information and to get control points through differential GPS. Main steps of the work: creation of a Digital Elevation Model (DEM), merging and geometric correction of the QuickBird image, mapping hydrology and geomorphology. Topographic features, such as slope, elevation and 3D views of the area were extracted from the DEM. Considering the morphologic and morphometric features of relief, the geomorphologic map was constructed at the $1 / 15,000$ scale. The drainage network was mapped in detail. At the area under study, the strong relief and the steep slopes made it difficult to get ground control points and to correct geometric distortions of the image used. Nevertheless, the high spatial resolution of the image allowed a detailed mapping of the area, optimizing field surveys. The results show that the QuickBird image is fully adequate for study the relief of high-elevation area with rough terrain.
\end{abstract}

Key Words: QuickBird image; Planalto das Araucárias; Geomorphologic map. 


\section{Introdução}

A análise do relevo possui grande importância nos diagnósticos ambientais, pois contribui para avaliar o quadro ambiental e para o planejamento do uso da terra (CHRISTOFOLETTI, 1994; ROSS, 2000). Nos diagnósticos ambientais há uma crescente demanda por mapas precisos e eficientes, visto que estes buscam uma integração de informações para auxiliar em processos de tomada de decisões.

Os novos satélites, capazes de adquirir imagens com alta resolução espacial da superfície terrestre, representam um avanço para análises ambientais. Durante um longo período, esses satélites foram exclusivos para uso militar (JACOBSEN, 2003). Hoje, a liberação das imagens orbitais com alta resolução para fins comerciais pode fornecer uma base de dados adequada para o mapeamento detalhado, em períodos mais curtos, com custos menores, competindo com levantamentos aerofotogramétricos (NALE, 2002; JACOBSEN, 2003).

Este trabalho analisa o potencial de imagens com alta resolução espacial (satélite QuickBird) para mapear o relevo do Planalto das Araucárias. A área teste foi o Centro de Pesquisas e Conservação da Natureza PRÓ-MATA. Técnicas de geoprocessamento foram usadas para executar o mapeamento e a análise integrada dos dados. As unidades geomorfológicas do PRÓ-MATA foram mapeadas e descritas, visando auxiliar pesquisas do meio físico, zoneamentos e planos de manejo da área (PINHEIRO, 2003).

\section{1. Área de estudo}

No âmbito de cooperação entre a Pontifícia Universidade Católica do Rio Grande do Sul (PUCRS) e a Universidade alemã de Tübingen foi criado o Centro de Pesquisas e Conservação da Natureza PRÓ-MATA, com o objetivo de desenvolver estudos e conservar a Mata Atlântica. O PRÓ-MATA possui 4.477,7246 ha, está localizado ao NE do Planalto das Araucárias entre as coordenadas $29^{\circ} 26^{\prime} 17^{\prime \prime}$ 'a $29^{\circ} 34^{\prime} 42^{\prime \prime}$ Sul e $50^{\circ} 08^{\prime} 14^{\prime \prime}$ a $50^{\circ} 14^{\prime} 18^{\prime \prime}$ Oeste de Greenwich (Figura 1).

O Planalto das Araucárias está inserido na Bacia do Paraná, suas regiões geológicas e geomorfológicas foram amplamente estudadas (LEINZ, 1949; Ab'SABER, 1949; ALMEIDA, 1956; IBGE, 1986; ROISENBERG, 1989; STEWART, et al. 1996; SCHERER, FACCINI e LAVINA, 2000), entre outros. A evolução desta região está relacionada a uma série de eventos vulcânicos e tectônicos associados à fragmentação do continente Gondwana e abertura do Oceano Atlântico Sul (VILLWOCK, 1999).

No Rio Grande do Sul, o Planalto das Araucárias está localizado no centro-leste, ocupando parte do Planalto dos Campos Gerais e escarpas da Serra Geral (Almeida, 1956; IBGE, 1986). Ao leste é limitado por escarpas abruptas voltadas para o Oceano Atlântico, ao sul limita-se por outra escarpa, em contato com a Depressão Central (ROISENBERG, 1989). A litologia compõe-se predominantemente de rochas eruptivas ácidas da Formação Serra Geral, que ocorrem sobrepostas ou intercaladas com rochas efusivas básicas, (ROISENBERG, 1989). Estas rochas são datadas do Mesozóico com idades entre 138 e 128 M.A. (STEWART et al., 1996). Acrescentam-se nesta composição, as rochas sedimentares, os arenitos da Formação Botucatu.

O clima na região do Planalto das Araucárias é temperado, mesotérmico e superúmido (IBGE, 1986). A temperatura média anual fica em torno dos $16^{\circ} \mathrm{C}$. No mês de janeiro são registradas as temperaturas mais elevadas, com médias de $29^{\circ} \mathrm{C}$, as temperaturas mínimas ocorrem em julho com médias de $7^{\circ} \mathrm{C}$. Durante os meses de inverno as temperaturas podem chegar a $0^{\circ} \mathrm{C}$ (Nimer, 1977). As precipitações anuais registram valores entre 1750 a 2500mm(IBGE, 1986).

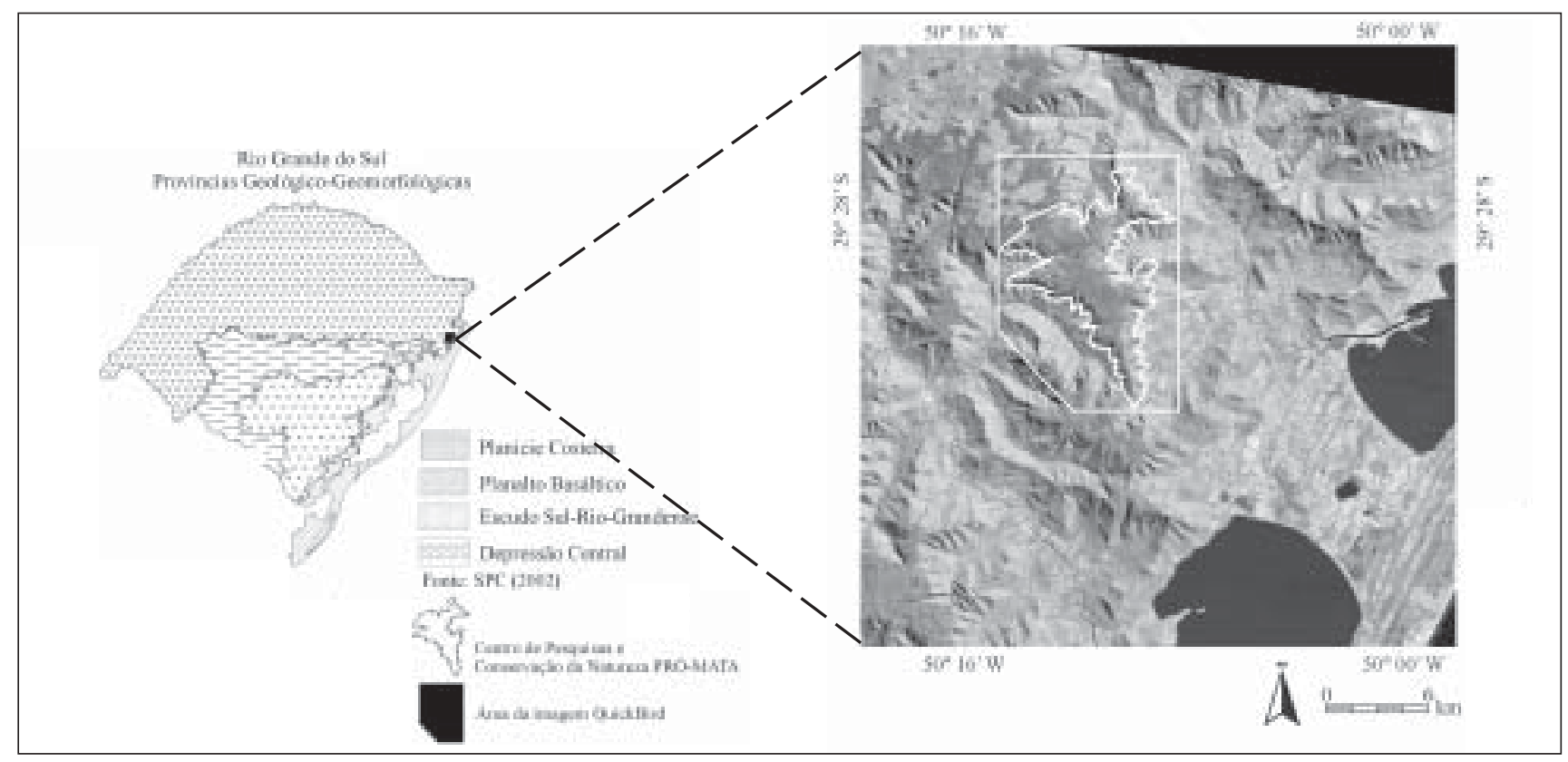

Figura 1: Localização da área de estudo. 


\section{Materiais e Métodos}

O satélite norte-americano QuickBird foi lançado em órbita em outubro de 2001. O QuickBird possui sensores do tipo CCD (Charge Coupled Device) flexíveis para visadas off-nadir até $30^{\circ}$ ao longo do terreno (TOUTIN e CHENG, 2002). A visada off-nadir permite a cobertura mais freqüente do terreno e que sejam adquiridas imagens com estereoscopia. As informações detalhadas sobre o QuickBird podem ser encontradas em Toutin e Cheng (2002) e Pinheiro (2003). A Tabela 1 descreve as especificações técnicas da imagem QuickBird utilizada neste trabalho.

Tabela 1: Especificações técnicas da imagem QuickBird utilizada no trabalho.

\begin{tabular}{|c|c|}
\hline Data de imageamento & $27 / 08 / 2002$ \\
\hline Ângulo de visada & $14^{0} 01^{\prime} 38,64^{\prime \prime}$ \\
\hline Resolução Espacial & $\begin{array}{l}\text { 0,70m Pancromática (PAN) } \\
\text { 2,80m Multiespectral }\end{array}$ \\
\hline & Pancromático: $0,450,90 \mu \mathrm{m}$ \\
\hline Resolução Espectral & $\begin{array}{l}\text { Azul: } 0,450,52 \mathrm{im} \\
\text { Verde: } 0,520,60 \mathrm{im} \\
\text { Vermelho: } 0,630,69 \mathrm{im} \\
\text { Infravermelho próximo } 0,760,90 \mu \mathrm{m}\end{array}$ \\
\hline Resolução Radiométrica & 16 bits $(65,536$ níveis de cinza) \\
\hline Área imageada & $\sim 10.882 \times 15.423 \mathrm{~m}$ \\
\hline
\end{tabular}

Neste trabalho, além das imagens com alta resolução, foram utilizados os seguintes dados:

- Imagem TM/Landsat-5 de 18/09/1999, órbita/ponto 220/81, bandas espectrais (vermelho, infravermelho próximo e infravermelho médio), resolução espacial de $30 \mathrm{~m}$;

- Curvas de nível obtidas a partir de cartas topográficas na escala 1/50000, folhas: SH.22-X-C - 2 MI - 2972/2 e SH.22 - X-C - 4 MI - 2955/4;
Um Modelo Digital de Elevação (MDE) foi gerado a partir da interpolação das curvas de nível das cartas topográficas (1/50000), para tanto foram utilizados a Rede Irregular de Triangulação (TIN) e o Interpolador Linear (PINHEIRO e KUX, 2003). O MDE possibilitou derivar mapas de declividades e altimetria, além de permitir gerar visualizações em 3D da área de estudo.

As imagens QuickBird foram fundidas para o obter imagens coloridas com maior resolução espacial. Neste contexto, foi feita uma fusão entre as bandas multiespectrais (menor resolução espacial) com a banda pancromática (PAN) (maior resolução espacial). No processamento foi aplicado o seguinte algoritmo (Steinmayer, 2002):

Nova imagem R: $\mathrm{r} * \mathrm{P}_{\mathrm{r}} / 100+\mathrm{PAN} *\left(100-\mathrm{P}_{\mathrm{r}}\right) / 100$

Nova imagem G: $\mathrm{g} * \mathrm{P}_{\mathrm{g}} / 100+\mathrm{PAN} *\left(100-\mathrm{P}_{\mathrm{g}}\right) / 100$

Nova imagem $\mathrm{B}: \mathrm{b} * \mathrm{P}_{\mathrm{b}} / 100+\mathrm{PAN} *\left(100-\mathrm{P}_{\mathrm{b}}\right) / 100$

Onde: R (Banda do Vermelho), G (Banda do Verde) e B (Banda do Azul). $\mathrm{P}_{\mathrm{r}}, \mathrm{P}_{\mathrm{g}}, \mathrm{P}_{\mathrm{b}}$ : Porcentagem das bandas, respectivamente, Vermelho, Verde eAzul. $r=$ Vermelho; $g=$ Verde; $b=$ Azul.

O Modelo Função Racional foi adotado para ortorretificar a imagem QuickBird (TAO e HU, 2001; TOUTIN e CHENG, 2002). Neste processamento foram empregados pontos controle, MDE e arquivos RPC (Coeficientes Polinomiais Racionais). Os pontos de controle foram adquiridos em expedições de campo com GPS Diferencial (coordenadas pós-processadas) (PINHEIRO, 2003).

Para análise e mapeamento das unidades geomorfológicas foram utilizadas as imagens QuickBird e TM, além de serem considerados dados de elevação e declividade, hidrografia e verificações em campo. As imagens QuickBird foram sobrepostas ao MDE, o que permitiu gerar visualizações em 3D que facilitaram o reconhecimento dos padrões de relevo. A interpretação e mapeamento da hidrografia foi feita na imagem PAN QuickBird. Os cursos d'água foram ordenados conforme a proposta de Strahler (1952) apud Christofoletti (1980). A figura 2 apresenta os procedimentos utilizados no mapeamento.

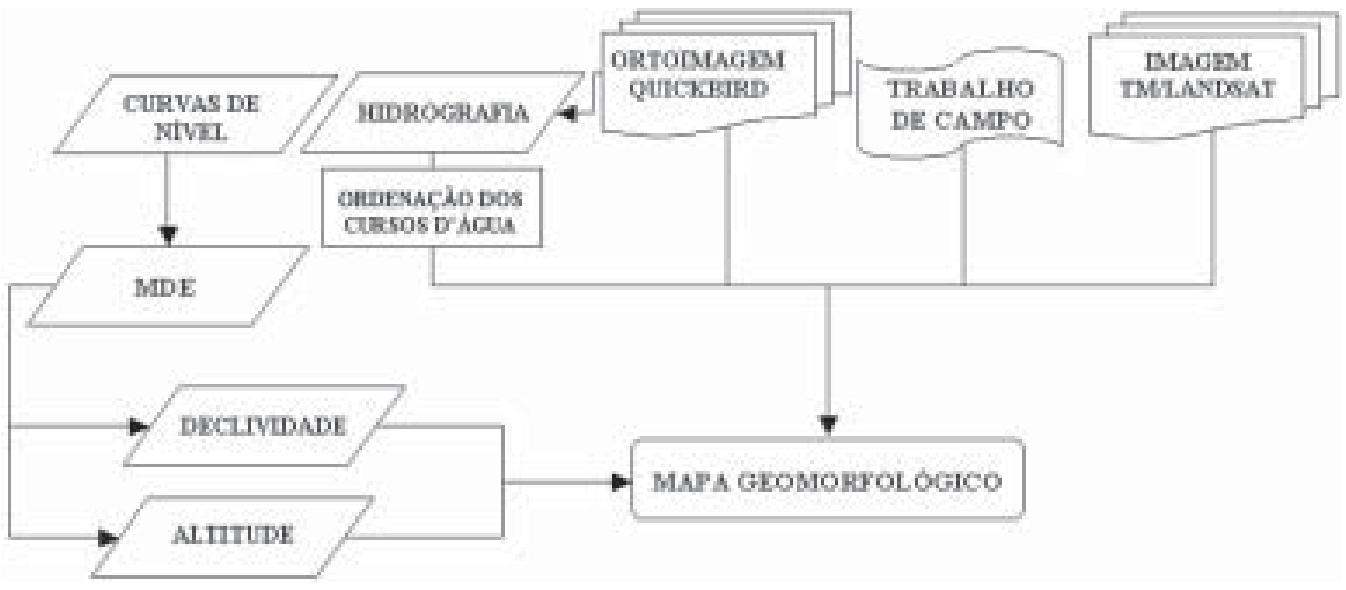

Figura 2: Fluxograma do mapeamento do relevo. 


\section{Resultados e discussão}

O processo de fusão entre as bandas pancromática e multiespectral do QuickBird (Tabela 1) permitiu obter imagens coloridas com resolução espacial de $0,70 \mathrm{~m}$ (PINHEIRO, 2003). A associação entre os dados texturais da imagem PAN com as cores das imagens MS possibilitou identificar detalhadamente feições no terreno. A Figura 3 apresenta um exemplo de uma área na qual são comparadas as imagens PAN e MS do QuickBird. Observe que em "A" as feições no terreno estão mais nítidas do que aquelas apresentadas em "B" e "C".
O Erro Médio Quadrático (RMS) da ortorretificação das imagens QuickBird PAN e fusão $(0,70 \mathrm{~m})$ foi de 3.22 pixels, utilizando 21 pontos de controle e 9 pontos para teste do processamento. O RMS para os pontos de controle foi de 2.62 pixels e para os pontos de teste foi de 4.15 pixels. Os resultados indicam que do ponto de vista da exatidão cartográfica o mapeamento pode ser realizado na escala 1/ 15000 classe "A" (PINHEIRO, 2003).

$\mathrm{Na}$ área mapeada o relevo é acidentando com vertentes íngremes e declividades acentuadas, isto dificultou a aquisição de pontos de controle, assim como a correção geométri-
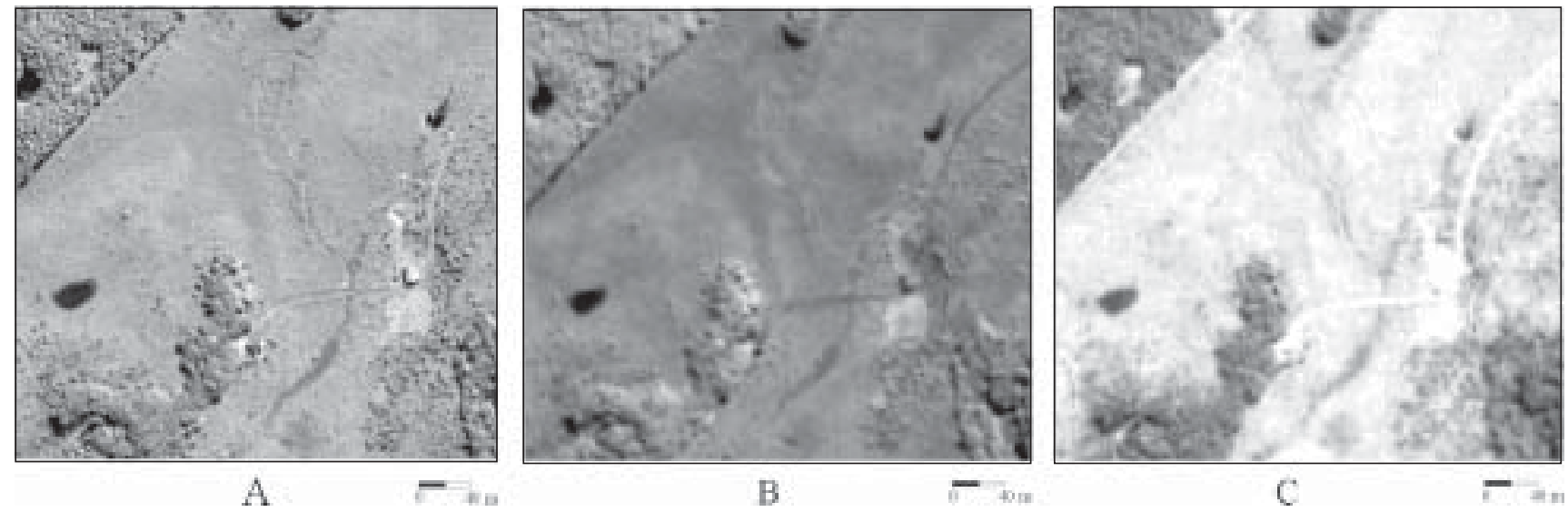

Figura 3: "A" - banda PAN QuickBird (0,70m). "B" - banda MS (infravermelho-próximo) $(2,8 m)$ e " $C$ ” - banda MS (verde) $(2,8 m)$.

ca da imagem QuickBird. Cerca de $20 \%$ da área possui declividades entre $30^{\circ}$ a $45^{\circ}$, ainda $38 \%$ apresentam declividades entre $15^{\circ}$ a $30^{\circ}$ (Tabela 2 ).

Tabela 2: Área ocupada pelas classes de declividade

\begin{tabular}{c|c|c|c}
\hline Classe & Declividade & Área (ha) & \% \\
\hline I & $0-5$ & 2589,53 & 16,9 \\
\hline II & $5-15$ & 2957,94 & 19,3 \\
\hline III & $15-30$ & 5811,87 & 38,0 \\
\hline IV & $30-45$ & 3151,39 & 20,6 \\
\hline V & $>45$ & 778,06 & 5,1 \\
\hline Total & & 15288,79 & 100,0 \\
\hline
\end{tabular}

O gradiente de altimetria é elevado na área de estudo, sendo condicionado por sua origem geológica e pelos processos erosivos devidos aos cursos d'água encaixados nas linhas de fraqueza. O Planalto é interrompido bruscamente por uma escarpa. Na área mapeada $23,1 \%$ apresenta altitudes superiores à $900 \mathrm{~m}$. Os fundos dos vales estão em média a uma altitude de $200 \mathrm{~m}$. A variação média de altitude entre o Planalto e os vales é de $700 \mathrm{~m}$, sendo que muitos deles formam cânions.

A rede de drenagem é controlada predominantemente por linhas de fraqueza, com lineamentos estruturais nas duas direções principais NO-SE e NE-SO (IBGE, 1986). Tais características foram de fácil interpretação nas imagens QuickBird, os cursos d'água possuem segmentos retilíneos, cotovelos, corredeiras e quedas d'água (Figura 4). No Planalto o padrão de drenagem dominante é o retangular, enquanto nas encostas é retilíneo (Figura 4).

A ordenação dos cursos d'água permitiu observar que na área de estudo cerca de $93 \%$ dos canais são de $1^{\mathrm{a}}$ e $2^{\mathrm{a}}$ ordem (Tabela 3). Considerando que todo curso d'água de primeira ordem possui uma nascente, foram identificadas 1431 nascentes, sendo que na área do PRÓ-MATA há 546 nascentes.

Tabela 3: Ordem dos canais de drenagem, freqüências e tamanhos.

\begin{tabular}{c|c|c|r|r}
\hline $\begin{array}{c}\text { Ordem } \\
\text { do canal }\end{array}$ & $\begin{array}{c}\text { Freqüência } \\
\text { do canal }\end{array}$ & $\begin{array}{c}\text { Freqüência } \\
\text { relativa }\end{array}$ & $\begin{array}{c}\text { Comprimento } \\
\text { total }(\mathbf{m})\end{array}$ & $\begin{array}{c}\text { Comprimento } \\
\text { médio }(\mathbf{m})\end{array}$ \\
\hline $1^{\text {a }}$ & 1431 & 0,734 & $365.013,20$ & 225,07 \\
\hline $2^{\mathrm{a}}$ & 395 & 0,203 & $152.702,23$ & 386,58 \\
\hline $3^{\mathrm{a}}$ & 95 & 0,049 & $84.058,34$ & 884,82 \\
\hline $4^{\mathrm{a}}$ & 26 & 0,013 & $41.636,76$ & $1.601,43$ \\
\hline $5^{\mathrm{a}}$ & 3 & 0,002 & $16.558,54$ & $4.139,64$ \\
\hline Total & 1950 & 1,000 & $659,969,07$ & $7.237,54$ \\
\hline
\end{tabular}

As interpretações das imagens QuickBird, TM/Landsat5 e os dados morfométricos permitiram gerar o mapa apresentado na Figura 5. A partir das análises dos dados foram identificadas, seis unidades geomorfológicas: Planalto dos Campos Gerais, Vertente escarpada da Serra Geral, Vertente 


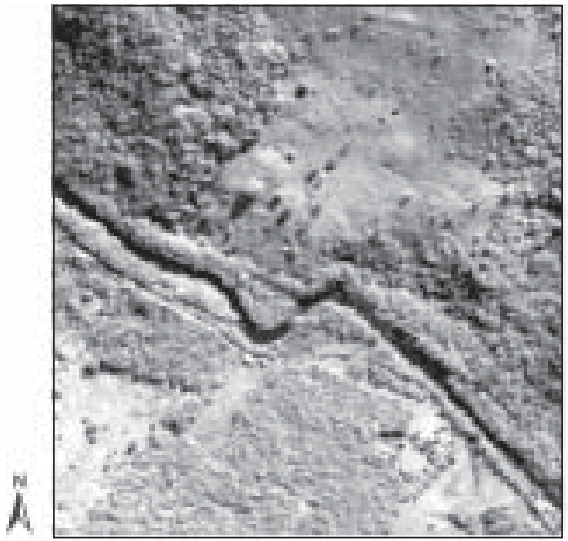

A $\overline{0} 50$ in

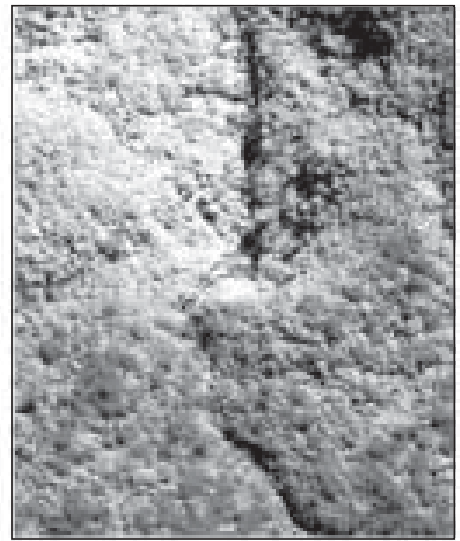

B

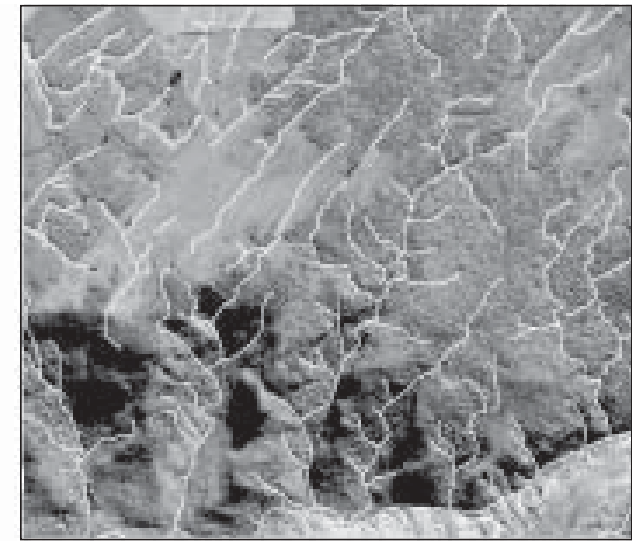

C

(1) 2901

Figura 4: "A" Detalhe do arroio Forqueta. "B" Queda d'água. "C" Escarpa do planalto, a drenagem aparece em branco.

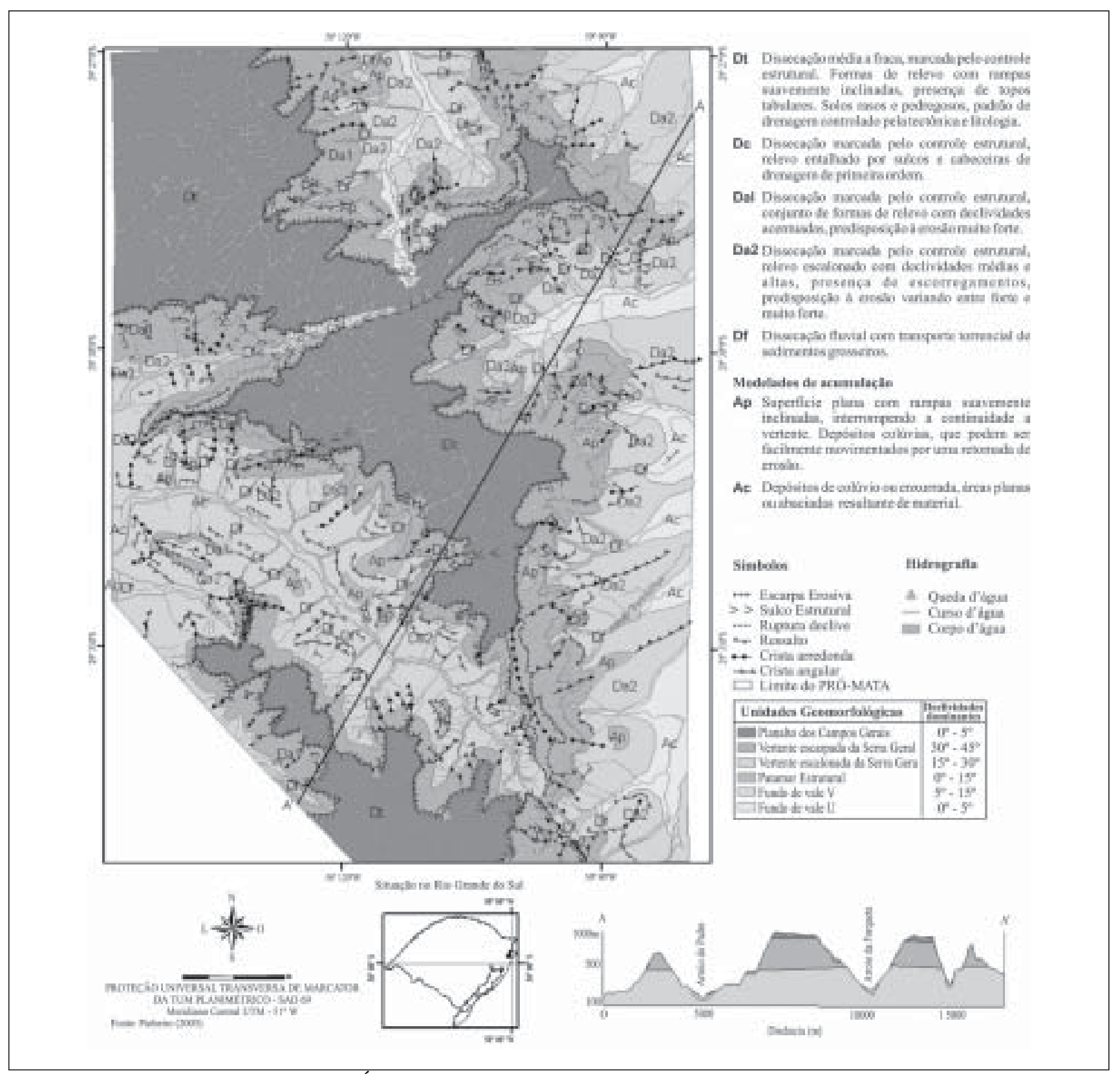

Figura 5: Mapa Geomorfológico do PRÓ-MATA e entorno. 
escalonada da Serra Geral, Patamar Estrutural, Fundo de Vale em "V" e Fundo de Vale em "U".

O Planalto dos Campos Gerais possui altitudes entre 900 a 980m. O relevo é suave-ondulado a ondulado, presença de topos tabulares, rampas suavemente inclinadas, superfícies aplainadas, colinosas com declividade média de $7^{\circ}$ (Figura 6). Nas baixadas verificam-se inúmeros corpos d'água, os quais dão origem a pequenos cursos d'água. As feições são planas desnudadas ou exumadas, as quais aparecem nas imagens QuickBird com textura lisa a pouco rugosas.

O clima úmido e chuvoso da região propicia que parte das precipitações infiltram-se nas fraturas, muitas destas alimentam o lençol freático.
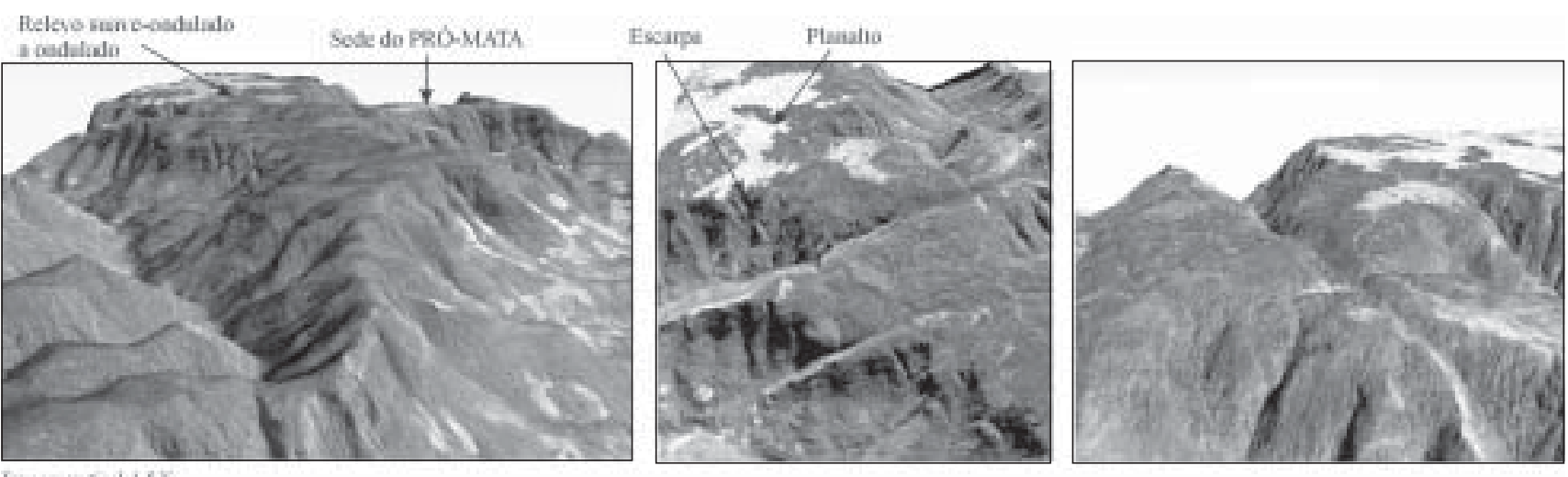

Figura 6: Visualizações em 3D da área de estudo.

Já o escoamento superficial remove o manto de alteração das rochas, formando os lajeados. Nas depressões onde há solos argilosos originamse os banhados, nestes locais se desenvolvem turfeiras em meio aos campos (VILLWOCK, 1998).

A Vertente escarpada da Serra Geral possui um elevado grau de instabilidade morfodinâmica, explicando movimentos de massa rápidos e esporádicos, como quedas de blocos, deslizamentos e movimentos de massa por rastejo. Este fato ocorre devido às formações superficiais e aos processos morfogenéticos associados à acumulação de água das chuvas, havendo saturação e com isso escorregamentos. As encostas são íngremes com declividades muito fortes, estas variam entre $30^{\circ}$ a $45^{\circ}$ e em alguns trechos as declividades possuem valores acima de $45^{\circ}$ (Figura 7).

Nas imagens QuickBird as frentes de escarpa estão bem definidas, configuram-se como uma borda dissecada do Planalto das Araucárias, onde estão presentes cristas alongadas, aguçadas e estreitas, anfiteatros de erosão e ressaltos escalonados (Figura 7). Nas encostas e anfiteatros, em zonas de fraturamento onde aflora o lençol freático, instala-se uma floresta exuberante, a Mata Atlântica (VILLWOCK, 1998).

A unidade geomorfológica Vertente escalonada da Serra Geral, assim como a unidade anterior, também é marcada pela ocorrência de quedas de blocos, deslizamentos e movimentos de massa por rastejo, e, na sua base instalam-se rampas de colúvio. As declividades dominantes variam entre $15^{\circ}$ a $30^{\circ}$ e as altitudes entre $160 \mathrm{~m}$ a $580 \mathrm{~m}$. Na imagem

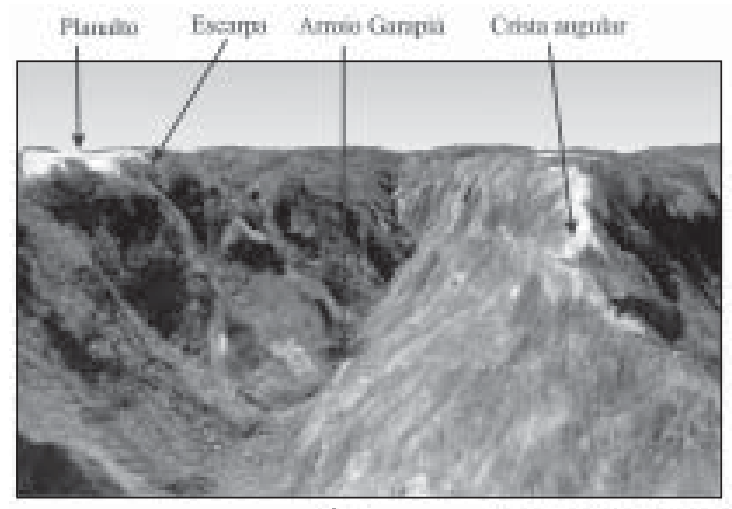

A

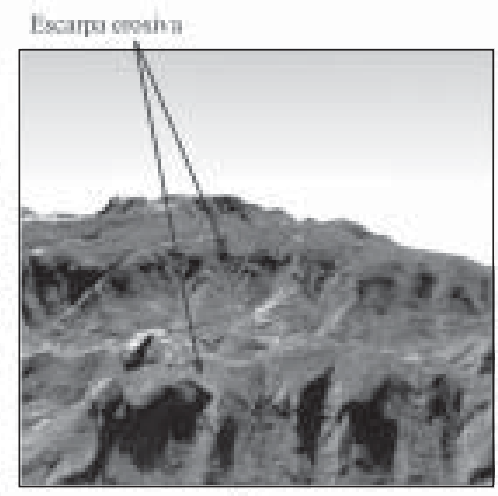

B

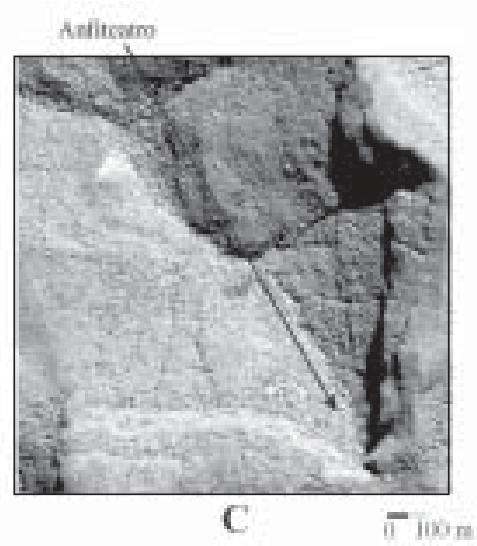

C $-100 \mathrm{~m}$

Figura 7: "A" - vale do arroio Garapiá, encostas íngremes, cristas alongas. "B" - visão 3D ilustrando as linhas de escarpa. "C" - sul do PRÓ-MATA observa-se um anfiteatro. 
QuickBird observam-se encostas com ressaltos bem marcados, estes são desníveis pouco acentuados cujo traçado pode ser relacionado ao controle estrutural ou litológico. Nas encostas, os perfis escalonados equivalem à cerca de uma dúzia de grandes derrames vulcânicos ocorridos na região (ALMEIDA, 1956). O nível de detalhamento das imagens QuickBird permite identificar com nitidez os ressaltos escalonados, podendo indicar, numa primeira aproximação, os contatos de alguns derrames de lavas vulcânicas ocorridos na área de estudo (Figura 8).
Os Patamares Estruturais ocorrem preferencialmente na altitude em torno de $550 \mathrm{~m}$, aparecendo nas imagens do QuickBird como feições aplainadas, suavemente inclinadas no meio das vertentes íngremes. Os Patamares estão presentes nas encostas da escarpa do Planalto das Araucárias, onde as rupturas de declive interrompem a continuidade do declive das vertentes. Suas declividades variam entre $0^{\circ}$ a $15^{\circ}$, mas, em suas bordas o declive pode variar entre $15^{\circ}$ a $30^{\circ}$, sendo áreas planas e/ou com pouco desnível.

$\mathrm{O}$ Fundo de vale em " $V$ " caracteriza-se por vales profun-

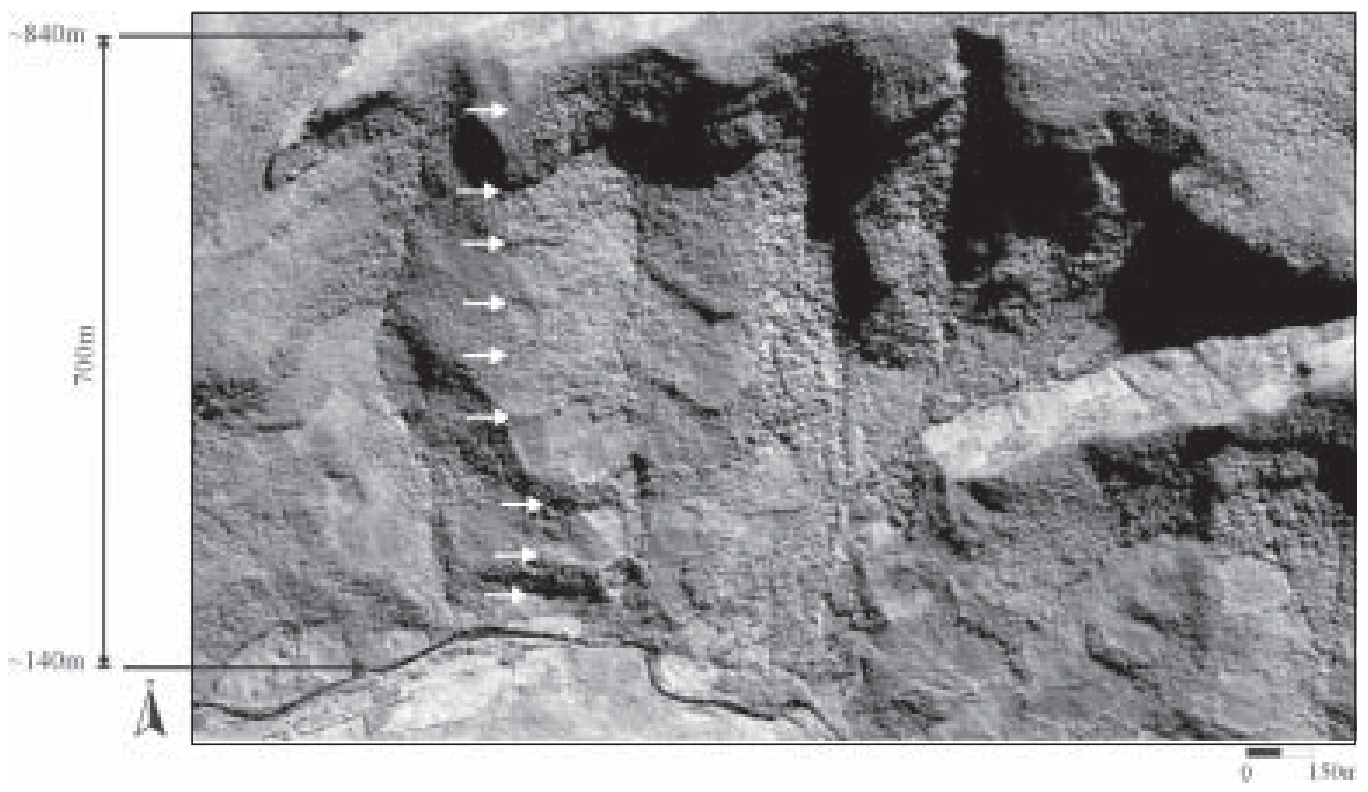

Figura 8: Imagem QuickBird, as setas em branco indicam os ressaltos escalonados.

dos com vertentes fortemente inclinadas. Nas observações de campo, verificou-se que os leitos dos cursos d'água são rochosos com corredeiras, existindo nos mesmos depósitos de carga detrítica, formada principalmente por material grosseiro como areias grossas, seixos e blocos rolados (Figura 9). A jusante do arroio Forqueta o canal torna-se mais largo, em torno de $26 \mathrm{~m}$ sendo que neste trecho é possível identifi- car bancos detríticos centrais. Ocorre a formação de ilhas a jusante do canal e a vegetação se desenvolve sobre o material depositado. Esta carga sedimentar é de fácil identificação nas imagens do QuickBird (Figura 9). Neste trecho as declividades são fracas $\left(0^{\circ}-5^{\circ}\right)$. Estes bancos estão relacionados com alta declividade, nos períodos de cheia ocorre a movimentação do material depositado.

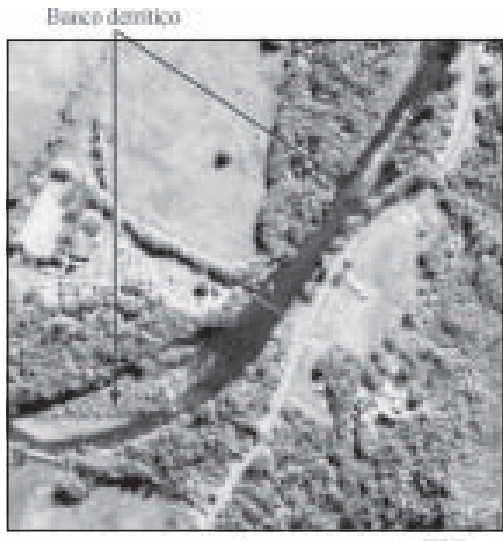

A

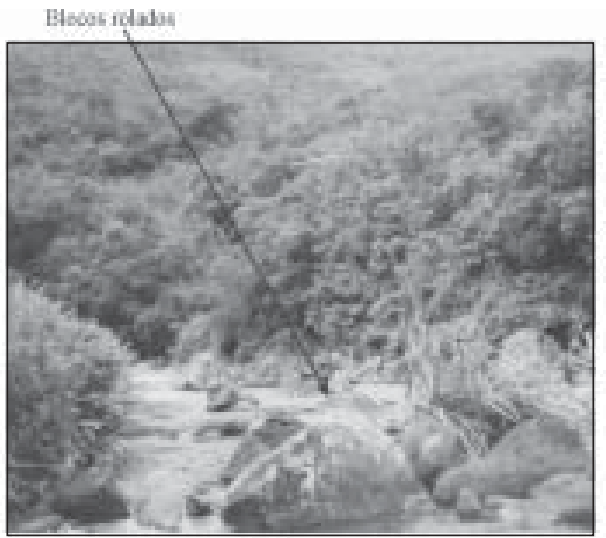

B

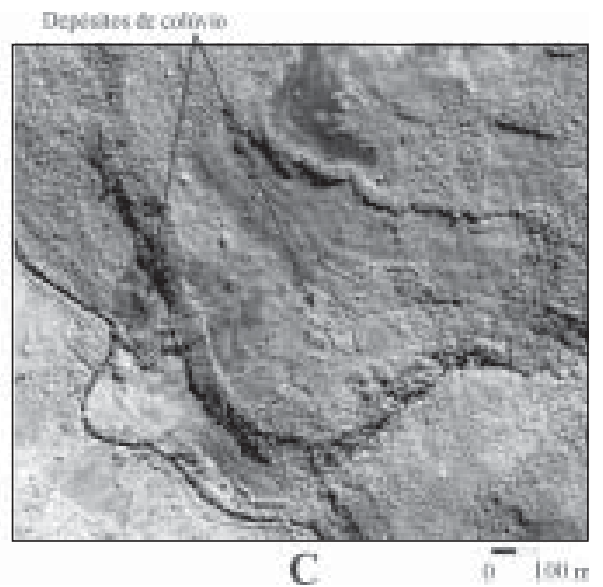

Figura 9: "A" bancos detríticos depositados no arroio Forqueta. "B" blocos rolados depositados no curso d'água. "C" rampas de colúvio na base das encostas. 
As imagens de satélites associadas às observações de campo permitiram concluir que na área estudada as vertentes da escarpa do Planalto voltado para leste, na direção do Oceano Atlântico, possuem vales mais abertos se comparados com aqueles direcionados para oeste (Figura 10).

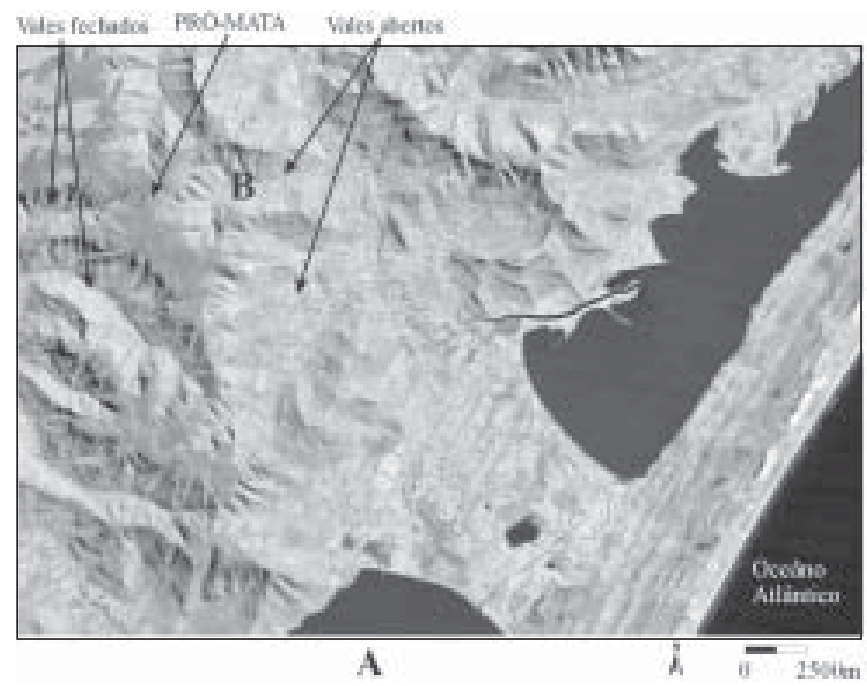

estereoscopia, as feições do relevo, assim como as unidades geomorfológicas do PRÓ-MATA, foram identificadas e mapeadas detalhadamente, através de elementos de fotointerpretação, tais como: textura, sombra, contexto, forma, padrão, tonalidade, etc. Neste contexto, sugere-se que novas pesquisas sejam realizadas,

Figura 10: "A" imagem TM/Landsat-5, visão sinótica da área de estudo. "B" detalhe do vale do arroio do Padre a rede de drenagem aparece em branco.

O Fundo de vales em " $U$ " são aplainados estando associados aos depósitos de sedimentos que foram erodidos das vertentes íngremes. As declividades dominantes variam entre $0^{\circ}$ a $5^{\circ}$, trata-se de uma área plana onde no sopé das vertentes íngremes há rampas de colúvio.

\section{Conclusão}

As imagens geradas pelo sistema sensor QuickBird possuem uma avançada tecnologia em termos de Sensoriamento Remoto orbital, para uso científico e comercial. Este estudo demonstrou que as imagens com alta resolução são adequadas para analisar e mapear o relevo de áreas acidentadas.

$\mathrm{Na}$ área de estudo, o relevo acidentado com altas declividades dificultou a aquisição dos pontos de controle e a correção geométrica das imagens QuickBird. Não obstante, a alta resolução espacial das imagens otimizou os trabalhos de campo.

A exatidão cartográfica das imagens QuickBird (1/ 15000), obtida através do Modelo Função Racional foi satisfatória para os objetivos deste estudo. Entretanto, provavelmente, os resultados da ortorretificação das imagens seriam melhores se existisse um MDE mais detalhado para área. A análise visual das imagens QuickBird utilizadas no estudo demonstram que estas atingem a escala 1:1000, permitindo identificar nitidamente os alvos no terreno.

Apesar das imagens usadas não permitirem pois a capacidade do QuickBird em adquirir imagens offnadir permite formar estéreos pares. Desta forma, possivelmente, informações adicionais do terreno poderiam ser identificadas a partir de imagens orbitais com estereoscopia.

Finalmente, conclui-se que as imagens orbitais de alta resolução espacial do QuickBird, e dos futuros satélites que serão desenvolvidos, podem ser usadas em diagnósticos ambientais, monitoramentos e planejamentos mais rotineiros e detalhados.

\section{Agradecimentos}

Os autores agradecem ao Instituto Nacional de Pesquisas Espaciais (INPE), Coordenação de Aperfeiçoamento de Pessoal de Nível Superior (CAPES), Pontifícia Universidade Católica do Rio Grande do Sul - Instituto do Meio Ambiente (PUCRS/IMA), a $1^{a}$ Divisão de Levantamento do Exército Brasileiro (1 $1^{\mathrm{a}}$ DL-DSG) e Universidade de Tübingen pelos diferentes suportes dados a este estudo. Agradecemos também as valiosas sugestões feitas pelos consultores da Revista Brasileira de Geomorfologia.

\section{Referências Bibliográficas}

Ab'Saber, A. N. (1949) Regiões de circundesnudação póscretácea no Planalto Brasileiro. Associação dos Geógrafos Brasileiros. Boletim Paulista de Geografia. n. 1. p. 3-21. 
Almeida, F.F.M. de. (1956) O Planalto Basáltico da Bacia do Paraná. Boletim Paulista de Geografia. n. 24. p. 3-34.

Christofoletti, A. (1994) Aplicabilidade do conhecimento geomorfológico nos projetos de planejamento. In: Guerra, A. J. T.; Cunha, S. B. da (org.) Geomorfologia: uma atualização de bases e conceitos. Rio de Janeiro: Bertrand Brasil. p. 415 - 440.

. (1980) Geomorfologia. São Paulo. Edgard Blücher, 2. ed. 188p.

Instituto Brasileiro de Geografia e Estatística - IBGE (1986) Folha SH. 22 Porto Alegre e parte da folha SH 21 Uruguaiana e SI 22 Lagoa Mirim. Rio de Janeiro, RJ: IBGE. 791p.(Projeto RadamBrasil, v. 33).

Jacobsen, K. (2003) Geometric Potential of Ikonos and QuickBird images. GIS - Geo-Information System. Journal for Spatial Information and Decision Making. v. 9. p.33$39,2003$.

Leinz, V. (1949) Contribuição à geologia dos derrames basálticos do sul do Brasil. Boletim da Faculdade de Filosofia, Ciências e Letras. São Paulo. n. 5, p. 61.

Nale,D.K. (2002)QuickBird-Aerial Photography Comparison Report. EMAP International., 39 p. Disponível em: <http:// www.digitalglobe.com>.Acessadoem: 6jun. 2003

Nimer, E. (1977) Clima. In: Instituto Brasileiro de Geografia e Estatística. Geografia do Brasil: Região Sul. v. 05. p.35-79.

Pinheiro, E. S. (2003) Avaliação de imagens QuickBird na análise geográfica de um setor da Mata Atlântica do Rio Grande do Sul. 173p. Dissertação (Mestrado em Sensoriamento Remoto), São José dos Campos: INPE-10094-TD/891. Disponível em: <www.iris.sid.inpe.br:1913>.

Pinheiro, E. S.; KUX, H.J.H. (2003) Análise e validação de Modelos Digitais do Terreno num setor de relevo escarpado da Mata Atlântica - RS, Área Teste: CPCN Pró-Mata. XI Simpósio Brasileiro de Sensoriamento Remoto. Belo Horizonte-MG. Abril 2003.
Roisenbberg, A. (1989) Petrologia e Geoquímica do vulcanismo ácido Mesozóico da Província Meridional da Bacia do Paraná. 285 p. Tese (Doutorado em Geociências) Porto Alegre: UFRGS

Ross, J. L. S. (2000) Geomorfologia ambiente e planejamento. 5 ed. São Paulo: Contexto. 85 p.

Scherer, C.M.S.; Faccini, U.F.; Lavina, E.L. (2000) Arcabouço estratigráfico do Mesozóico da Bacia do Paraná. In: Holz, M. e Deros, L.F (ed) Geologia do Rio Grande do Sul. Porto Alegre:Edição CIGO/UFRGS. p. 335-354.

Secretaria de Coordenação e Planejamento SPC/RS (2002) Atlas Sócio-Econômico do Estado do Rio Grande do Sul. SPC. Porto Alegre, $2^{\mathrm{a}}$.ed. 86p.

Steinamayer, M. (2002) Algoritmo para fusão de imagens -ENVI (mensagem pessoal). Mensagem recebida por eduardo@ltid.inpe.br10 nov. 2002.

Stewart, K.; Turner, S.; Kelly, S.: Hawkesworth, C. Kirsten, L. Mantovani, M. (1996) 3-D ${ }^{40} \mathrm{Ar}-{ }^{39} \mathrm{AR}$ geochronology in the Paraná continental flood basalt province. Earth and Planetary Science Letters, v. 143, p.95-109.

Tao, V.; Y, HU. (2001) A comprehensive study of the rational function model for photogrammetric processing. Photogrammetric Engineering and Remote Sensing. v.67, n. 12p. $1347-1357$. Dec.

Toutin, Th; Cheng, P. (2002) QuickBird - a milestone for high resolution mapping. Earth Observation Magazine, v.11, n.4.p.14-18.

Villwock, J.A. (1999) OPlanalto, a Serra e a Planície Costeira: Um passeio geológico pelo norte do Rio Grande do Sul. In: ELY, N. H.; BARROSO, V.L. M. (org.) Raízes de Terra de Areia. Porto Alegre: EST p. 400 - 419.

(1998) São Francisco de Paula e o Planalto das Araucárias: um ponto de vista geológico. In: Richter, M. (org.) Conservação da biodiversidade e desenvolvimento sustentável de São Francisco de Paula - um plano de ação preliminar. Porto Alegre: EDIPUCRS. p. 53-64. 